\title{
Comparison of benzimidazole nucleosides and ganciclovir on the in vitro proliferation and colony formation of human bone marrow progenitor cells
}

\author{
M. Reza Nassiri, ${ }^{1}$ * Stephen G. Emerson, ${ }^{2}$ Rodrigo V. Devivar,${ }^{3}$ Leroy B. Townsend, ${ }^{3}$ John C. Drach ${ }^{1,3}$ \\ and Russell S. Taichman ${ }^{4}{ }^{1}$ Department of Biologic and M aterials Science, ${ }^{2}$ Department of Periodontics/Geriatrics/ \\ Prevention, School of Dentistry, ${ }^{3}$ Department of M edicinal Chemistry, College of Pharmacy; U niversity of M ichigan, \\ Ann Arbor, M ichigan, and ${ }^{4}$ Departments of Internal M edicine and Pediatrics, University of Pennsylvania, Philadelphia, \\ Pennsylvania, U.S.A.
}

Received 11 September 1995; accepted for publication 30 January 1996

\begin{abstract}
Summary Recently we have shown that certain benzimidazole ribonucleosides are potent and selective inhibitors of human cytomegalovirus (HCMV) replication. Because antiviral drugs used to treat HCMV and human immunodeficiency virus (HIV) infections can suppress marrow progenitors, we have evaluated the most promising of the new benzimidazoles for their effects on human bone marrow cells in vitro. In an initial study of the bone marrow toxicity of one of the most active compounds, $100 \mu \mathrm{m}$ 2-bromo-5,6dichloro-1-( $\beta$-D-ribofuranosyl)-benzimidazole (BDCRB) inhibited cell proliferation by $20 \%$ over a $10 \mathrm{~d}$ period compared to $52 \%$ inhibition by $100 \mu \mathrm{M}$ ganciclovir, the drug currently most used to treat HCMV infections. The effects of these drugs and selected other benzimidazole nucleosides were evaluated more extensively in haemopoietic progenitor cell colony formation assays. Colony formation was determined at 2 weeks and scored as either burst forming units-erythroid (BFU-E), or colony forming units-granulocyte/macrophage (CFU-GM). At the highest concentration tested, $100 \mu \mathrm{M}$ BDCRB only moderately affected BFU-E or CFU-GM formation
\end{abstract}

( $31 \%$ and $47 \%$ inhibition, respectively). This concentration is 10 -fold higher than that required to produce a 10000 -fold reduction in virus titre. Evaluation of the 2-chloro analog of BDCRB (TCRB) which is less potent against HCMV, its $5^{\prime}$ deoxy analog (5'-dTCRB) which is more potent, and the 2unsubstituted compound (DRB) gave the following order of haemopoietic toxicity: DRB $>$ TCRB $\geqslant 5^{\prime}$-dTCRB > BDCRB. In contrast to the benzimidazoles, ganciclovir decreased colony formation by $84 \%$ for BFU-E and $86 \%$ for CFU-GM at $100 \mu \mathrm{m}$. These results establish that certain benzimidazole nucleosides are less toxic to haemopoietic progenitors than the preferred drug now being used clinically for HCMV infections. The results also establish that different structureactivity relation shipsexist for antiviral activity and progenitor cell toxicity, thereby suggesting that different mechanismsare involved in the two types of drug action.

Keywords: antivirals, bonemarrow toxicity, colony formation, erythroid, granulocyte/macrophage.
Human cytomegalovirus (HCMV) infections are frequent complications of bone marrow and solid organ transplantation and are particularly dangerous for patients with either congenital or acquired immunodeficiencies (Alford \& Britt, 1993; McKenzie et al, 1991; Rubin, 1990). The striking morbidity and mortality often associated with these infections necessitates the development of effective treatments which

\footnotetext{
* Present address: Department of Pharmacology, Lake Erie College of Osteopathic Medicine, Erie, PA 16509, U.S.A.

Correspondence: Dr John C. Drach, Department of Biologic and Materials Sciences, School of Dentistry, University of Michigan, Ann Arbor, MI 48109-1078, U.S.A.
}

are not further detrimental to the host. Although a number of compounds inhibit HCMV replication in vitro, only the acyclic nucleoside ganciclovir (Faulds \& Heel, 1990) and the pyrophosphate analog foscarnet (Palestine et al, 1991) are currently approved by the U.S. Food and Drug Administration to treat HCMV infections. Both drugs, however, have poor oral bioavailability. The use of ganciclovir can lead to granulocytopenia, anaemia, leucopenia and thrombocytopenia (Von Bueltzingsloewen et al, 1993; Appelbaum et al, 1988; Scadden et al, 1994); therapy with foscarnet may produce renal dysfunction (Chrisp \& Clissold, 1991). Moreover, virus strains resistant to each of these drugs have been identified (Knox et al, 1991; Drew, 1991; Field \& Biron, 1994). 
<smiles>[R]CC1O[C@@H]2[C@@H](n3c([R2])nc4cc(Cl)c(Cl)cc43)O[C@H]1[C@H]2O</smiles><smiles>Nc1nc2c(ncn2COC(O)CO)c(=O)[nH]1</smiles>

\section{BDCRB: $\quad \mathbf{R}=\mathrm{OH}, \mathrm{R}_{2}=\mathrm{Br} \quad$ Ganciclovir TCRB: $\quad \mathrm{R}=\mathrm{OH}, \mathrm{R}_{2}=\mathrm{Cl}$ DRB: $\quad \mathrm{R}=\mathrm{OH}, \mathrm{R}_{2}=\mathrm{H}$ 5'-dTCRB: $\mathrm{R}=\mathrm{H}, \quad \mathrm{R}_{2}=\mathrm{Cl}$}

Fig 1. Structures of benzimidazole nucleosides and ganciclovir. Abbreviations: 2-bromo-5,6-dichloro-1-( $\beta$-D-ribofuranosyl)benzimidazole, BDCRB; the 2-chloro analog, TCRB; the 2-unsubstituted analog, DRB (Tamm et al, 1954), and the $5^{\prime}$-deoxy analog of TCRB, $5^{\prime}$-dTCRB.

Consequently there remains a need for the development of more efficacious and less toxic agents to treat HCMV infections.

Recently we have shown that a novel class of benzimidazole ribonucleosides selectively inhibits HCMV replication in vitro with antiviral activity well separated from cytotoxicity in uninfected human cells (Townsend et al, 1995) (Fig 1). The mechanism by which these agents inhibit HCMV replication appears to be unique, interfering with a late stage of viral assembly (Drach et al, 1992) which does not involve inhibition of DNA synthesis (Drach et al, 1992; Underwood et al, 1993) but does involve inhibition of DNA processing (Underwood et al, 1993, 1994).

Other antiviral agents with activity against HCMV or HIV exhibit significant marrow toxicity. Consequently identifying the effects of benzimidazole ribonucleosides on bone marrow progenitors is an integral component of moving these agents toward clinical trial and obtaining a better understanding of their specificity. We report herein the in vitro effects of four benzimidazole nucleosides on colony formation by human haemopoietic erythroid and granulocyte/macrophageprogenitors. We also evaluated the effects of the most promising compound on the stimulated proliferation of heterogenous bone marrow mononuclear cells and compared all of these effects to those produced by ganciclovir, the antiviral drug most frequently used to treat HCMV infections.

\section{METHODS}

Investigational compounds and stock solutions. 2,5,6-Trichloro1-( $\beta$-D-ribofuranosyl)benzimidazole (TCRB), its $2-\mathrm{Br}$ analog (BDCRB) and the $5^{\prime}$-deoxy analog of TCRB (5'-dTCRB) were synthesized in the laboratories of Professor $L$. B. Townsend at the University of Michigan as described elsewhere (Townsend et al, 1995; Drach et al, 1995). The 2-unsubstituted analog of TCRB, originally described by Tamm et al (1954) and termed DRB by them, was obtained from Sigma Chemical Co., St
Louis, Mo. Ganciclovir was kindly provided by Syntex Corp. (Palo Alto, Calif.). Structuresfor all compoundsaregiven in Fig 1. Drug stocks were initially prepared at concentrations of $50 \mathrm{mg} / \mathrm{ml}$ in DMSO. Stocks were further diluted with assay medium (see below) to desired final concentrations. The highest concentration of drug used $(100 \mu \mathrm{m})$ contained $<0.4 \%$ DMSO in the assays. In control experiments, no appreciable differences in colony formation was noted between $0.4 \%$ DMSO and untreated controls.

Human bone marrow cells. Human bone marrow cells were obtained from healthy adult volunteers by iliac crest puncture and aspiration under a protocol approved by the University of Michigan's Human Subject Committee. Marrow cells were diluted 1:4 in Iscove's modified Dulbecco medium (IMDM) and separated by density separation on Ficoll-hypaque (specific gravity 1.077) (Sigma Chemical Co.) to recover mononuclear cells. To remove monocytes, platelets and megakaryocytes, two rounds of plastic adherence at $37^{\circ} \mathrm{C}$ were performed for $1 \mathrm{~h}$ each in modified Dexter medium [IMDM, 10\% fetal bovine serum, 10\% horse serum, $100 \mu \mathrm{g} /$ $\mathrm{ml}$ penicillin and streptomycin and $1 \mu \mathrm{m}$ hydrocortisone (Life Technologies, Grand Island, N.Y.)]. The non-adherent cells were then recovered and incubation continued overnight in modified Dexter medium.

Proliferation of bone marrow cells in liquid culture. Proliferative response of non-adherent bone marrow mononuclear cells to BDCRB or ganciclovir was evaluated in liquid suspension culture. Bone marrow cells were recovered as described above and resuspended in Dexter medium supplemented with 2 units $/ \mathrm{ml}$ erythropoietin, $20 \mathrm{ng} / \mathrm{ml}$ GM-CSF and $10 \mathrm{ng} / \mathrm{ml} \mathrm{IL-3}$ in 24-well tissue culture plates (Falcon, Becton-Dickinson, N.J.) at a final density of $1 \times 10^{5}$ cells $/ \mathrm{ml}$. After $24 \mathrm{~h}, \mathrm{BDCRB}$, ganciclovir or vehicle were added directly to give noted final concentrations. After $10 \mathrm{~d}$, the absolute cell number and percent viability were determined by manual haemocytometer counting of a minimum of 200 cells in PBS containing $0.4 \%$ trypan blue.

$M$ ethylcelluloseassay. Bonemarrow cellswere washed three times in PBS following the overnight incubation. Aliquots of $5 \times 10^{4}$ non-adherent low-density mononuclear cells were plated in $1 \mathrm{ml}$ methylcellulose (Methocult H4330, StemCell Technologies Inc., Vancouver, B.C.) supplemented with 2 units $/ \mathrm{ml}$ erythropoietin (StemCell Tech Inc.), $20 \mathrm{ng} / \mathrm{ml}$ GM-CSF and $10 \mathrm{ng} / \mathrm{ml}$ IL-3 (Life Technologies) using triplicate-grided $35 \mathrm{~mm}$ dishes (Nunc, Naperville, III.). Plates were incubated for 2 weeks under fully humidified conditions in an atmosphere of $5 \% \mathrm{CO}_{2}$ and $5 \% \mathrm{O}_{2}$ at $37^{\circ} \mathrm{C}$. Where indicated, selected concentrations from 1 to $100 \mu \mathrm{m}$ of a benzimidazole nucleoside or ganciclovir, or vehicle, were directly incorporated into the methylcellulose. Colonies of $>50$ cells were scored at 10 - or 20 -fold magnification with a darkfield or other stereomicroscope (Nikon, Garden City, N.Y.) for burst forming units-erythroid (BFU-E), or colony forming units-granulocyte/macrophage(CFU-GM).

Analysis of drug effects. Dose-response relationships were used to compare drug effects. These were constructed by linearly regressing the probit of percent inhibition of the parameters derived in the preceding sections against log drug concentrations. $50 \%$ inhibitory concentrations $\left(\mathrm{IC}_{50} \mathrm{~S}\right)$ 


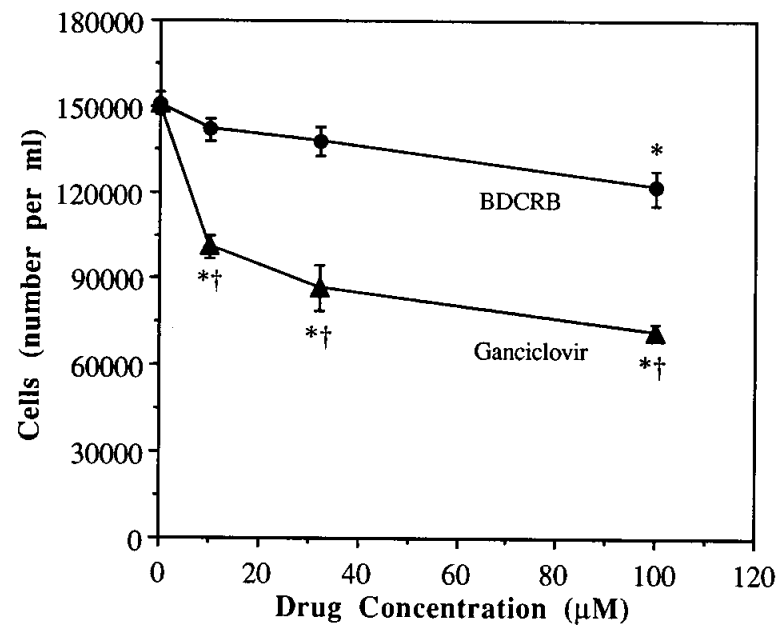

Fig 2. Effect of BDCRB and ganciclovir on proliferation of human bone marrow mononuclear cells. $1 \times 10^{5}$ cells from a representative marrow donor were incubated at $37^{\circ} \mathrm{C}$ in triplicate for $10 \mathrm{~d}$ with or without test agents in $1 \mathrm{ml}$ liquid cultures containing growth factors. Absolute numbers of cells are presented as mean \pm standard deviation of triplicate determinations performed on day 10 . *Indicates a significant difference from untreated controls $(P<0.001)$; † Indicates a significant difference from BDCRB $(P<0.001)$.

and corresponding confidence intervals were calculated from the regression lines by the method described by Goldstein (1964). Statistical significanceshown in the figures was determined by ANOVA.
RESULTS

Effects of BDCR B and gancidovir on the proliferation and viability of bone marrow cells in liquid culture

In an initial study to determine the toxicity of BDCRB to bone marrow cells, we compared the effects of BDCRB and ganciclovir on the in vitro proliferation and viability of a mixed population of non-adherent bone marrow cells from healthy adult volunteers over a $10 \mathrm{~d}$ period. During this time, the number of cells in untreated cultures increased 1.5 -fold $\left(1 \times 10^{5}\right.$ to $1.5 \times 10^{5} \pm 3.8 \times 10^{3} \mathrm{cell} / \mathrm{ml}$ in triplicate assays). In the presence of BDCRB, cell proliferation was significantly inhibited only at $100 \mu \mathrm{m}$ (see Fig 2). In contrast, ganciclovir inhibited cell proliferation over the entire dose range tested $(10-100 \mu \mathrm{m})$. It also was significantly more inhibitory than BDCRB at all concentrations (Fig 2). A 50\% inhibitory concentration $\left(\mathrm{IC}_{50}\right)$ was not reached for BDCRB compared to $71 \mu \mathrm{m}$ for ganciclovir.

As a measure of whether or not the observed effects of BDCRB and ganciclovir on bone marrow cell proliferation were due to inhibition of proliferation or overt toxicity, trypan blue dye exclusion assays were performed at the end of the $10 \mathrm{~d}$ assay. Similar to the results described above, viability of the cells treated with concentrations of BDCRB up to $32 \mu \mathrm{m}$ differed little from untreated samples $(94.6 \pm 1.5 \%$ in triplicateassays at $32 \mu \mathrm{m}$ compared to $98 \pm 1 \%$ for untreated cells). At $100 \mu \mathrm{M}$, however, cell viability declined to $90.3 \pm$ $3.5 \%$. In comparison, the viability for ganciclovir at $100 \mu \mathrm{M}$ was $80 \pm 2 \%$. Therefore, based upon the fact that BDCRB inhibits the replication of HCMV by 50 to $>99 \%$ at $0 \cdot 7-2 \mu \mathrm{M}$ (Table I) (Townsend et al, 1995), its antiviral dose range is

Tablel. Comparison of the effects of benzimidazole nucleosidesand ganciclovir on human bonemarrow progenitor cells and human cytomegalovirus replication.

\begin{tabular}{|c|c|c|c|c|}
\hline \multirow[b]{2}{*}{ Drug } & \multicolumn{4}{|c|}{$50 \%$ inhibitory concentration $(\mu \mathrm{M})$} \\
\hline & BFU-E* & CFU-GM* & Cytotoxicity in HFF cellst & HCMV replication \\
\hline BDCRB & $>100 \ddagger$ & $213 \pm 184 \S$ & 118 & 0.7 \\
\hline TCRB & $48 \pm 8$ & $62 \pm 3$ & 238 & $2 \cdot 9$ \\
\hline DRB & $2 \cdot 7 \pm 0.5$ & $8.6 \pm 2.9$ & 24 & 42 \\
\hline $5^{\prime}-d T C R B$ & $13(8 \cdot 2-18)$ & $103(61-328)$ & 77 & 0.35 \\
\hline Ganciclovir & $21 \pm 4 \cdot 8$ & $19 \pm 11$ & $>100$ & 8 \\
\hline
\end{tabular}

\footnotetext{
$* 50 \%$ inhibitory concentrations were determined from four sets of dose-response curves (derived in four separate experiments from four separatedonors) for ganciclovir, three for BDCRB, two for TCRB and DRB, and one for $5^{\prime}$-dTCRB. $\mathrm{IC}_{50} \mathrm{~S}$ were calculated from the separate dose- responsecurves which were constructed from triplicate assays of three to five drug concentrations, including those shown in Figs 3 and 4 . I $\mathrm{C}_{50} \mathrm{~S}$ are presented \pm standard deviations from the replicate experiments. Results with $5^{\prime}$-dTCRB are presented with $95 \%$ confidence intervals calculated from five-point dose-response curves because data are from single experiments.

† Data obtained from HCMV plaque reduction assays in human foreskin fibroblasts (HFF cells); cytotoxicity determined by visual inspection of HFF cells not infected by the virus in plaque assay. All data are means of replicate experiments as presented previously in Townsend et al (1995) and Drach et al (1995).

$\ddagger 50 \%$ inhibitory concentration much higher than could be extrapolated from dose-responsecurves with $100 \mu \mathrm{m}$ as highest concentration.

$\S$ Large standard deviation because an $\mathrm{IC}_{50}$ extrapolated by linear regression from one dose-response curve (data from the donor shown in Fig 4) was much greater than $100 \mu \mathrm{m}$, the highest concentration tested. Without data from this experiment the value would be $83 \pm 16$.
} 


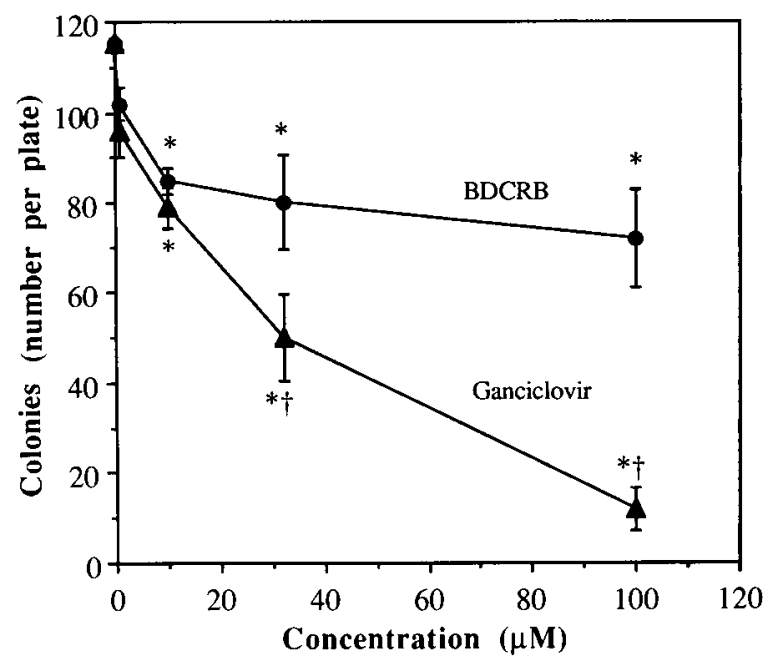

Fig 3. Effect of BDCRB and ganciclovir on erythroid colony (BFU-E) formation by human bonemarrow progenitors. $5 \times 10^{4}$ cellsfrom the same marrow donor used to obtain data in Fig 4 were plated in triplicate with or without compounds and incubated for 2 weeks. Following the incubation period, plates were examined and scored for development of BFU-E. Data are presented as mean \pm standard deviation of the triplicate determinations. See legend to Fig 2 for definition of symbols.

well separated from concentrations which inhibited bone marrow cell proliferation and viability.

\section{Effects of benzimidazoles and gancidovir on the formation of} erythroid colonies (BFU-E)

To further determine whether haemopoietic toxicity is a significant feature of the benzimidazole ribonucleosides, we evaluated the effects of BDCRB and the three analogs on BFU$E$ and compared the resultsto those obtained with ganciclovir. For these studies, non-adherent low-density mononuclear cells were plated directly into methylcellulose containing growth factors and test compound in selected concentrations ranging from 1 to $100 \mu \mathrm{m}$. Over this concentration range, BDCRB had a minimal effect on BFU-E formation (Fig 3). At a concentration as high as $100 \mu \mathrm{m}$, which is 10 -fold higher than that required to produce a 10000 -fold reduction in virus titre (Townsend et al, 1995), there was $32 \pm 8 \%$ inhibition of erythroid colony formation in three experiments. In contrast, ganciclovir decreased BFU-E formation by $84 \pm 6 \%$ at this concentration in four experiments. Furthermore, those colonies that did form at intermediate concentrations of ganciclovir were of smaller size. Data from this experiment and the replicate experiments were combined to calculate $\mathrm{IC}_{50} \mathrm{~S}$ (Table I). These data confirm there were marked differences in the effect of BDCRB and ganciclovir on erythroid progenitors.

In a similar manner, the effects of TCRB, DRB, and $5^{\prime}$ dTCRB on BFU-E were examined. TCRB - which is less potent against HCMV - was more toxic to erythroid progenitor cells $\left(I C_{50}=48 \mu \mathrm{m}\right.$, Table I) than was BDCRB. The compound with the most potent activity against $\mathrm{HCMV}, 5^{\prime}$-dTCRB, was about 4-fold more toxic than TCRB to erythroid progenitor cells

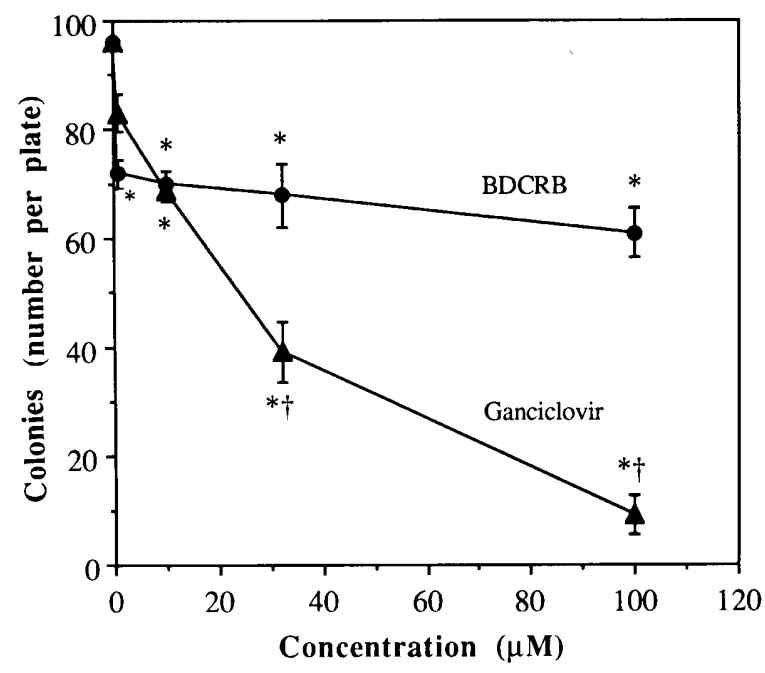

Fig 4. Effect of BDCRB and ganciclovir on granulocyte/macrophage colony formation by human bone marrow progenitors. $5 \times 10^{4}$ cells from a representative marrow donor were plated in triplicate with or without compounds and incubated for 2 weeks. Following the incubation period, plates were examined and scored for development of CFU-GM. Data are presented as mean \pm standard deviation of the triplicate determinations. See legend to Fig 2 for definition of symbols.

$\left(I C_{50}=13 \mu \mathrm{m}\right)$ but was 8-fold more active against HCMV. The 2-unsubstituted analog DRB was the most toxic to erythroid precursors and also had the least activity against HCMV. Thus there was no correlation between the structure-activity relationship for potency against the virus and that for toxicity to erythroid progenitors.

Effects of benzimidazoles and gancid ovir on the formation of granulocyte/ macrophage colonies (CFU-GM)

In as much as neutropenia is often a primary negative consequence of ganciclovir therapy, we also determined effects of the compounds on granulocyte/macrophage precursors. Similar to BFU-E development, BDCRB was significantly less inhibitory for CFU-GM development compared to ganciclovir (Fig 4). Little difference in the inhibition of colony formation was noted between 10 and $32 \mu \mathrm{m}$ of BDCRB. At $100 \mu \mathrm{m}$, a concentration 100-fold above the level at which BDCRB is active in the plaque assay (Table I), there was a $47 \pm 9 \%$ reduction in $\mathrm{G} / \mathrm{M}$ colonies in three separate experiments. In contrast, ganciclovir was significantly more toxic to $\mathrm{G} / \mathrm{M}$ colony formation than $\mathrm{BDCRB}$, resulting in reductions in the development of CFU-GM of $86 \pm 9 \%$ at $100 \mu \mathrm{m}$. Similar differences were observed in $I_{50}$ values calculated from all points on the dose- response curves (Table I).

The effects of TCRB, DRB and $5^{\prime}$-dTCRB on CFU-GM also were examined. Data from separate experiments showed that, like the results with erythroid precursors, TCRB was more toxic to granulocyte/macrophage progenitor cells $\left(\mathrm{IC}_{50}=\right.$ $62 \mu \mathrm{M}$ ) than was BDCRB (Table I). Unlike results from the BFU-E assay, the 5'-deoxy analog of TCRB was less toxic in a single experiment than TCRB to granulocyte/macrophage 
progenitor cells. In this assay as well as in the BFU-E assay, DRB was the most toxic compound (Table I). Taken together, these in vitro data suggest that BDCRB is significantly less toxic to human bone marrow cells compared to ganciclovir and the other benzimidazole nucleosides. The relatively low toxicity of BDCRB to human bone marrow cells, together with its potent antiviral activity, make this novel compound an excellent candidatefor more detailed study as a potential drug to treat human CMV infections.

\section{DISCUSSION}

Benzimidazole ribonu cleosidesare a novel class of compounds with the potential to be developed as drugs for human CMV infections. At present, the use of ganciclovir to treat HCMV infections and certain other antiviral agents to treat other infections produces significant bone marrow toxicity. Therefore it is important to identify new agents which exhibit minimal effects on the bone marrow while limiting virus replication. This is particularly true for individuals with pre-existing immunocompromised states which may be due to viral infections such as individuals with AIDS (Castella et al, 1985; Treacy et al, 1987; Perkocha \& Rodgers, 1988). As a model of bone marrow suppression and to evaluate the potential safety of this class of HCMV inhibitors for human use, we compared the effect of selected benzimidazole nucleosides to ganciclovir on haemopoietic progenitor cells in vitro.

The results of this investigation have established that BDCRB is significantly less inhibitory for the formation of human bone marrow erythroid and granulocyte-macrophage colonies than is ganciclovir. Although a decrease in colony formation was noted with $100 \mu \mathrm{M} \mathrm{BDCRB}$ (Figs 3 and 4), this concentration is 10 -fold greater than that needed to give at least a 10000 -fold reduction in HCMV titre (Townsend et al, 1995). In contrast, ganciclovir at $100 \mu \mathrm{M}$ decreased colony formation by approximately $85 \%$ for BFU-E and CFU-GM (Figs 3 and 4). It is of interest to compare the effects of the drug concentrations used in this in vitro study to drug concentrations observed in vivo. When BDCRB was administered intraven ously to mice or monkeys at $10 \mathrm{mg} / \mathrm{kg}$, plasma levels ranged from 3 to $5 \mu \mathrm{m} 1 \mathrm{~h}$ post dose (Good et al, 1994). These concentrations are well within the in vitro antiviral dose range but below levels we now have found to inhibit bone marrow progenitors. When ganciclovir was administered intravenously to people at $5 \mathrm{mg} / \mathrm{kg}$, plasma levels of approximately $35 \mu \mathrm{m}$ were obtained at $1 \mathrm{~h}$ (Roche Laboratories, 1996; Fletcher et al, 1986). This also is within its antiviral dose range but is a concentration sufficient to inhibit bone marrow progenitors.

Despite the fact that inhibition by BDCRB was weak, the data (Results section and Table I) suggest that there was a greater effect on granulocyte/macrophage precursors than on erythroid precursors. Depending on the donor, the $I_{50}$ for BFU-E were well in excess of $100 \mu \mathrm{m}$, which was the highest concentration tested. Extrapolation of the dose-response lines by linear regression projected $\mathrm{IC}_{50} \mathrm{~S}$ of $400-1400 \mu \mathrm{m}$. Although these values probably over-estimate true values, they are significantly higher than the $\mathrm{IC}_{50} \mathrm{~S}$ for
CFU-GM formation which ranged from 67 to $472 \mu \mathrm{M}$. In contrast, minor differences were noted for effects of ganciclovir on the two lines of precursor cells $\left(\mathrm{IC}_{50} \mathrm{~S}\right.$ for BFU-E and CFU-GM ranged from 14 to $28 \mu \mathrm{M}$ and from 4 to $34 \mu \mathrm{M}$, respectively, for separate donors). These $\mathrm{IC}_{50} \mathrm{~S}$ for ganciclovir are higher than those reported in some other studies. For example, Scadden et al (1994) reported $I_{50} S$ of 0.8 and $1.4 \mu \mathrm{M}$, respectively, for BFU-E and CFU-GM, and Lewis et al (1994) reported $I C_{50} S$ of 4.6 and $12.3 \mu \mathrm{M}$, respectively. We have no explanation for these differences other than to note that growth and assay condition swere different in each of the studies. Regardless, all of these in vitro findings are consistent with the neutropenia reported for ganciclovir in several clinical studies (Snoek et al, 1990; Winston et al, 1988; Buhles et al, 1988).

More significant differences in effects were observed among the benzimidazole nucleosides than between BDCRB and ganciclovir. The observation that TCRB was somewhat more toxic than BDCRB is opposite to their effects on HCMV replication where BDCRB is the more potent compound. It also is different from visual cytotoxicity produced by the two compounds in stationary HFF cells (Table I). In addition, the apparent lesser effect of BDCRB on erythroid precursors is different from the other benzimidazoles. TCRB, $5^{\prime}$-dTCRB and DRB all had more potent effects on erythroid precursors than on granulocyte/macrophage precursors (Table I). The most striking difference among the benzimidazoles is the greater toxicity of DRB compared to its analogs. Together with our prior results (Townsend et al, 1995), these data establish that changes in the molecule profoundly affect not only activity against HCMV but also marrow toxicity. Comparing results for BDCRB and DRB establishes that the addition of a bromine atom to the 2-position of DRB (to give BDCRB) not only increased antiviral activity by over 50 -fold, it also decreased marrow toxicity by approximately 20 -fold. Such great differences in antiviral activity and cytotoxicity for such closely related molecules virtually proves that different biochemical targets are being affected in HCMV-infected cells compared to human bone marrow progenitors.

We have not directly examined the effects of BDCRB on the bone marrow microenvironment, including the capacity of bone marrow stromal cells to support haemopoietic progenitorsin long-term bonemarrow cultures. Thesestudies will be important in the future, because the pathogenesis of HCMV-induced myelosuppression is not clearly understood but probably is related to a direct toxic effect on bone marrow stromal cells. Evidence for the ability of HCMV to alter stromal cell competence in supporting haemopoiesis comes from investigation s where CMV-infected stromal cells fail to su stain CFU-GM growth in vitro (Lagneaux et al, 1994). Furthermore, when HCMV-infected stromal/haemopoietic cell cultures are supplemented with exogenous cytokines including G-CSF, GM-CSF, IL-3 and IL-6 the combination completely restored the CFU activity (Snoek et al, 1990). These data strongly suggest that modulations in cytokine production by the stromal microenvironment results directly from HCMV infections. Therefore it will be of interest to determine the effect of benzimidazole nucleosides on the bone marrow microenvironment either at the level of stromal cell's ability to 


\section{M. Reza Nassiri et al}

support haemopoiesisor at the level of the haemopoietic stem cells.

In summary, we have found that BDCRB is significantly less toxic in vitro to erythroid and granulocytic/macrophage progenitors than is the current drug of choice for HCMV infections, ganciclovir. Although BDCRB exhibited a slight inhibitory effect on proliferation of a mixed population of bone marrow cells, the effects were minimal relative to those produced by ganciclovir. The relatively low haemotoxicity of BDCRB, its minimal effects on haemopoiesis in vitro, together with its potent antiviral activity are excellent properties for a compound to have when it is intended for the control of human CMV infections.

\section{ACKNOW LEDGMENTS}

The authors thank Melissa Fenner and Melissa Tuck for providing the human bone marrow, and Marcelle Jennifer Reilly for her technical assistance. We appreciate many helpful suggestions and discussion with Ronna E. Dornsife, of Glaxo Wellcome PLC, Research Triangle Park, N.C. This study was supported by N.I.H. grant UO1-AI31718 for a NCDDG-Ol from the National Institute of Allergy and Infectious Diseases.

\section{REFERENCES}

Alford, C.A. \& Britt, W.J. (1993) Cytomegalovirus. The Human Herpesviruses (ed. by B. Roizman, R. J. Whitley and C. Lopez), pp. 227-255. Raven Press, New York.

Appelbaum, F.R., Meyers, J.D., Deeg, J., Schuening, T.G.F. \& Storb, R. (1988) Toxicity trial of prophylactic 9-[2-hydroxy-1-(hydroxymethyl) ethoxymethyl] guanine (ganciclovir) after marrow transplantation in dogs. Antimicrobial Agents and Chemotherapy, 32, 271-273.

Buhles, W.C., Mastre, B.J., Tinker, A.J., Strand, V. \& Kortez, S.H., Syntex Collaborative Ganciclovir Treatment Group (1988) Ganciclovir treatment of life- or sight-threatening cytomegalovirus infection: experience in 314 immunocompromised patients. Review of Infectious Diseases, 3, S495-S506.

Castella, A., Croxson, T.S., Mildvan, D., Witt, D.H. \& Zalusky, R. (1985) The bone marrow in AIDS: a histologic, hematologic, and microbiologic study. American Journal of Clinical Pathology, 84, 424432.

Chrisp, P. \& Clissold, S.P. (1991) Foscarnet: a review of its antiviral activity, pharmacokinetic properties and therapeutic use in immunocompromised patients with cytomegalovirus retinitis, Drugs, 41, 104-129.

Drach, J.C., Bush, P.M., Ptak, R.G., Devivar, R.V., Townsend, L.B., Davis, M.G., Underwood, M.R. \& Biron, K.K. (1995) Halogenated benzimidazole $5^{\prime}$-deoxyribonucleosides are potent and selective inhibitors of human cytomegalovirus replication. 35 th Interscience Conference on Antimicrobial Agents and Chemotherapy, San Francisco, Abstract $\mathrm{H} 112$.

Drach, J.C., Townsend, L.B., Nassiri, M.R., Turk, S.R., Coleman, L.A., Devivar, R.V., Genzlinger, G., Kreske, E.D., Renau, T.R., Westerman, A.C. \& Shipman, C., Jr, Biron, K.K., Dornsife, R. \& Kern, E.R. (1992) Benzimidazole ribonucleosides: a new class of antiviralswith potent and selective activity against human cytomegalovirus. Antiviral Research, 21, (Suppl. 1), 49.

Drew, W.L. (1991) Clinical use of ganciclovir for cytomegalovirus infection and the development of drug resistance Journal of Acquired Immunodeficiency Syndrome, 1, S42-S46.

Faulds, D. \& Heel, R.C. (1990) Ganciclovir: a review of its antiviral activity, pharmacokinetic properties and therapeutic efficacy in cytomegalovirus infections. Drugs, 39, 597-638.

Field, A.K. \& Biron, K.K. (1994) 'The end of innocence' revisited: resistance of herpesviruses to antiviral drugs. Clinical Microbiology Review, 7, 1-13.

Fletcher, C., Sawchuk, R., Chinnock, M.T., de Miranda, P. \& Balfour, H.H., Jr (1986) Human pharmacokinetics of the antiviral drug DHPG. Clinical Pharmacology and Therapeutics, 40, 281-286.

Goldstein, A . (1964) A nalysis of a singlecurve with graded responses. Biostatistics: an Introductory Text, pp. 156-161. MacMillan, New York.

Good, S.S., Owens, B.S., Townsend, L.B. \& Drach, J.C. (1994) The disposition in rats and monkeys of 2-bromo-5,6-dichloro-1-( $\beta$-Dribofuranosyl)-benzimidazole (BDCRB) and its 2,5,6-trichloro congener (TCRB). Antiviral Research, 23, (Suppl. 1), 103.

Knox, K.K., Drobyski, W.R. \& Carrigan, D.R. (1991) Cytomegalovirus isolate resistant to ganciclovir and foscarnet from marrow transplant patient. Lancet, 337, 1292-1293.

Lagneaux, L., Delforge, A., Snoek, R., Stryckmans, P. \& Bron, D. (1994) Decreased production of cytokines after cytomegalovirus infection of marrow-derived stromal cells. Experimental Hematology, 22, 26-30.

Lewis, A.F., Drach, J.C., Fennewald, S.M., Huffman, J.H., Ptak, R.G., Sommadossi, J-P., Revankar, G.R. \& Rando, R.F. (1994) Inhibition of human cytomegalovirus in culture by alkenyl guanineanalogs of the thiazolo[4,5-d ]pyrimidinering system. Antimicrobial Agents and Chemotherapy, 38, 2889-2895.

McKenzie, R., Travis, W.D. \& Masur, H. (1991) The causes of death in patients with human immunodeficiency virus infection: a clinical and pathological study with emphasis on the role of pulmonary diseases. M edicine, 70, 326-343.

Palestine, A.G., Polis, M.A., Smet, M.D., Baird, B.F., Falloon, J, Kovacs, J.A., Davey, R.T., Zurlo, J.J., Zunich, K.M., Davis, M., Hubbard, L., Brothers, R., Ferris, F,L., Chew, E., Davis, J.L., Rubin, B.I., Mellow, S.D., Metcalf, J.A., Mansichewitz, J., Minor, J.R., Nussenblatt, R.B., Masur, H. \& Lane, C. (1991) A randomized, controlled trial of foscarnet in the treatment of cytomegalovirus retinitis in patients with AIDS. Annals of Internal M edicine, 11, 665-673.

Perkocha, L.A. \& Rodgers, G.M. (1988) Hematologic aspects of human immunodeficiency virus infection: laboratory and clinical considerations American Journal of Hematology, 29, 94-105.

Roche Laboratories (1996) Cytovene ${ }^{\circledR}$ IV (ganciclovir for injection). Physicians' Desk Reference, 50th edn, pp. 2104-2110.

Rubin, R.H. (1990) Impact of cytomegalovirus infection on organ transplant recipients. Review of Infectious Diseases, 12, S754- 766.

Scadden, D.T., Wang, A., Zsebo, K.M. \& Groopman, J.E. (1994) In vitro effects of stem-cell factor or interleukin-3 on myelosuppression associated with AIDS. AIDS, 8, 193-196.

Snoek, R., Langneaux, L., Delforge, A., Bron, D., Van der Auwera, P., Stryckmans, P., Balzarini,J. \& DeClercq, E. (1990) Inhibitory effects of potent inhibitors of human immunodeficiency virus and cytomegalovirus on the growth of human granulocyte-macrophage progenitor cells in vitro. European Journal of Clinical M icrobiology and Infectious Diseases, 9, 615-619.

Tamm, I., Folkers, K., Shunk, C.H. \& Horsfall, F.L. (1954) Inhibition of influenza virus multiplication by $\mathrm{N}$-glycosides of benzimidazoles. Journal of Experimental M edicine, 99, 227-250.

Townsend, L.B., Devivar, R.V., Turk, S.R., Nassiri, M.R. \& Drach, J.C. (1995) Design, synthesis, and antiviral activity of certain 2,5,6trihalo-1-( $\beta$-D-ribofuranosyl) benzimidazoles. Journal of M edicinal Chemistry, 38, 4098-4105. 
Treacy, M., Lai, L., Costello, C. \& Clark, A.L. (1987) Peripheral blood and bone marrow abnormalities in patients with HIV-related disease British Journal of Haematology, 65, 289-294.

Underwood, M.R., Biron, K.K., Hemphill, M.L., Miller, T.J., Stanat, S.C., Dornsife, R.E., Drach, J.C., Townsend, L.B., Edwards, C.A \& Harvey, R.J. (1993) High molecular weight HCMV DNA does not properly mature in the presence of 2-bromo-5,6-dichloro-1- $\beta$-D-ribofuranosylbenzimidazole (BDCRB). Herpesvirus Workshop, Pittsburgh, Pa., July 1993.

Underwood, M.R., Stanat, S.C., Drach, J.C., Harvey, R.J. \& Biron, K.K. (1994) Inhibition of HCMV DNA processing by a new class of
anti-HCMV compounds is mediated through the UL89 gene product. Herpesvirus Workshop, Vancouver, B.C., August 1994. Von Bueltzingsloewen, A., Bordigoni, P., Witz, F., Bene, M.C., Schmitt, C., Lacour, B. \& Sommelet, D. (1993) Prophylactic use of ganciclovir for allogenic bone marrow transplant recipients. B one M arrow Transplantation, 12, 197-202.

Winston, D.J., Ho, W.G., Bartini, K., Holland, G.N., Mitsuya, R.T., Gale, R.P., Busuttil, R.W. \& Champlin, R.E. (1988) Ganciclovir therapy for cytomegalovirus infections in recipients of bone marrow transplants and other immunocompromised patients. Review of Infectious Diseases, 3, 547-553. 